\title{
BMJ Open Multilevel ecological analysis of the predictors of spanking across 65 countries
}

Kaitlin Paxton Ward (D , ${ }^{1}$ Andrew Grogan-Kaylor, ${ }^{2}$ Garrett T Pace, ${ }^{2}$ Jorge Cuartas, ${ }^{3}$ Shawna Lee ${ }^{2}$

To cite: Ward KP, GroganKaylor A, Pace GT, et al. Multilevel ecological analysis of the predictors of spanking across 65 countries. BMJ Open 2021;11:e046075. doi:10.1136/ bmjopen-2020-046075

- Prepublication history for this paper is available online. To view these files, please visit the journal online (http://dx.doi. org/10.1136/bmjopen-2020 046075).

Received 19 0ctober 2020 Accepted 02 June 2021
Check for updates

(C) Author(s) (or their employer(s)) 2021. Re-use permitted under CC BY-NC. No commercial re-use. See rights and permissions. Published by BMJ.

${ }^{1}$ School of Social Work, Department of Psychology, University of Michigan, Ann Arbor, Michigan, USA

${ }^{2}$ School of Social Work, University of Michigan, Ann Arbor, Michigan, USA

${ }^{3}$ School of Education, Harvard University, Cambridge, Massachusetts, USA

Correspondence to Kaitlin Paxton Ward; kpward@umich.edu

\section{ABSTRACT}

Objective Ending violence against children is critical to promote the health and socioemotional development of children across the globe. To this end, the UNICEF and the WHO have called for the abolishment of spanking, which is the most pervasive form of physical violence against children worldwide. This study used an ecological perspective to examine micro-level and macro-level predictors of parental spanking across 65 countries. Participants Data came from the fourth and fifth rounds of the UNICEF Multiple Indicator Cluster Surveys, which were administered between 2009 and 2017 ( $N=613861$ households). We examined the predictors of spanking using multilevel logistic regression analysis.

Results Micro-level factors (ie, those observed at the familial level) were stronger predictors of spanking in comparison to macro-level factors (ie, those observed at the community and country level). Caregiver belief that children need physical punishment in order to be raised properly was the largest risk factor for spanking $(\mathrm{OR}=2.55$, $p<0.001)$. Older child age, the child being female, the head of the household having a secondary education or higher, and higher household wealth were protective factors against spanking, while a higher number of people living in the household was a risk factor for spanking. Living in an urban community was the only macro-level factor associated with spanking.

Conclusions Intervention at the micro-level and macrolevel are important to reduce violence against children across the globe.

\section{INTRODUCTION}

Ending violence against children is a global public health priority. The United Nations Convention of the Rights of the Child and the United Nations Sustainable Development Goals have established that eliminating all forms of violence against children is necessary in order to promote health and wellbeing across the lifespan. ${ }^{12}$ One of the most common forms of violence against children is spanking, defined as physically hitting a child on the bottom with a bare hand. ${ }^{34}$ Worldwide, more than one in four caregivers view physical punishment as a necessary part of child rearing, and nearly two in three

\section{Strengths and limitations of this study}

This is the largest study on the predictors of spanking to date.

- Data used in this study are representative of the populations living within each sample cluster.

- Multilevel modelling accounted for between-country and within-country variation in spanking.

- This study uses cross-sectional data; therefore, causal inferences cannot be made.

- This study does not examine mechanisms linking micro-level and macro-level predictors to spanking.

children experience physical punishment in the home. ${ }^{56}$ Spanking harms human dignity and is a violation of children's rights, ${ }^{17}$ with rigorous evidence showing that spanking impairs children's social, emotional and behavioural functioning. ${ }^{8-11}$

As such, there is a global effort to ban spanking in all settings including the home. ${ }^{12}$ Sixty-two countries to date have implemented legal bans on forms of parental punishment that use violence, including spanking. ${ }^{13}$ Professional organisations such as the UNICEF, ${ }^{8}$ the $\mathrm{WHO}^{14}$ and the American Academy of Pediatrics ${ }^{15}$ have called for the end of spanking. Bans have been associated with lower levels of community violence and can increase public awareness regarding violence against children. ${ }^{1617}$ Further, researchers have called for the global implementation of evidence-based interventions that reduce the use of parental spanking. ${ }^{12}$ However, to inform these global efforts, it is necessary to examine the role of risk and protective factors for spanking across cultures.

The ecological systems model ${ }^{18}$ suggests that multiple factors at the individual, microsystem and macrosystem levels influence caregiver utilisation of spanking. The microsystem refers to the immediate environment in which the child is raised (eg, child and family functioning), whereas the 
macrosystem refers to the broader context (eg, culture and policies) that may influence parent-child interactions. At the micro-level, boys, preschool-aged children, children living with many members in the household and children who have caregivers who believe spanking is appropriate are at higher risk of physical and psychological abuse. ${ }^{3} 19$ Children living in households with higher economic security and higher educational attainment tend to be at lower risk of abuse and harsh forms of punishment. ${ }^{20-22}$

At the macro-level, community violence, gender inequality and higher unemployment rates have all been shown to increase the likelihood of child abuse. ${ }^{62-25}$ However, global studies on the predictors of spanking are sparse, with most studies including spanking as part of a larger physical punishment scale ${ }^{3}$ or predicting spanking among a smaller sample of countries (see Lansford and Deater-Deckard, ${ }^{25}$ which examines predictors of spanking across 24 countries). This study aims to provide a global examination of the micro-level and macro-level predictors of spanking across 65 countries, the majority of which are low-income and middle-income countries (LMICs). The micro-level and macro-level predictors examined in this study were informed by prior research ${ }^{20-25}$ showing a broad range of factors are associated with risk of punishment and abuse; we are aware of no prior studies that examine all of these risk factors on a comparable global scale.

\section{METHOD}

\section{Patient and public involvement}

Data came from the UNICEF Multiple Indicator Cluster Surveys (MICS). Since 1995, UNICEF has been administering MICS in over 100 LMICs to examine overall health and well-being, especially among women and children. MICS data are used to improve the lives of individuals who are most vulnerable by informing policy decisions, informing programme intervention, tracking changes in indicators related to Millennium Development Goals and influencing the public opinion on the state of women and children's health on a global level. UNICEF uses multistage cluster sampling, wherein households are randomly chosen within clusters. The surveys are comparable across countries and representative of the population living within each sampling area, making these surveys useful for informing and shaping policies. All participants provided informed consent prior to completing the surveys. Further details about the data can be found on the MICS website (https://mics.unicef.org/about). We examine two of the more recent surveys, specifically the fourth (MICS4) and fifth (MICS5) rounds, which were conducted between 2009 and 2013 and between 2012 and 2017, respectively.

\section{Participants}

Within each household selected within a sampling area, a trained fieldworker administered a household questionnaire in-person with the head of household; if the head of household was unavailable, then the head of household's partner or another adult residing in the household was interviewed. Using a random number table, the fieldworker randomly chose a child (between the ages of 2 and 17 for MICS4 and 1 and 17 for MICS5) within the household to be the focal child for the interview. Questions about discipline strategies, including spanking, were not asked if the focal child were between the ages of 15 and 17. Our sample included survey responses from households within 65 countries that had publicly released data as of July 2020 (see table 1).

\section{Measures}

Spanking

Spanking was measured through a modified version of the Parent-Child Conflict Tactics Scale, ${ }^{26}$ which asked the respondent whether they or anyone else in the household had 'spanked, hit, or slapped [the focal child] on the bottom with a bare hand' in the past month $(0=n o, 1=y e s)$.

\section{Microsystem predictors}

Child age was continuous and measured in years; a linear and squared term were included because the relationship between child age and spanking has been shown to be curvilinear in prior literature. ${ }^{19}$ Child sex was dichotomously coded $(0=$ male, $1=$ female $)$. The educational attainment of the head of the household was categorical (1=none (comparison category), 2=primary, $3=$ secondary plus). The number of household members was continuous and capped at 50. Whether the respondent believed that a child needs physical punishment in order to be raised properly was dichotomously coded $(0=n o$, $1=y e s)$. The household wealth score was standardised within each country and modelled as a categorical variable to reflect quintiles ( $1=$ poorest (comparison), $2=$ second poorest, $3=$ middle, $4=$ second richest, $5=$ richest ). To account for head-of-household characteristics, we also included headof-household sex $(0=$ female, $1=$ male $)$ and whether the head of household was the focal child's biological parent $(0=$ no, $1=$ yes $)$.

\section{Macrosystem predictors}

Macro-level predictors were measured at the same year for each of the MICS surveys. The homicide rate was continuous and measured per 100000 inhabitants. ${ }^{27}$ The unemployment rate was also continuous. ${ }^{28}$ Human development was continuous and measured with the Human Development Index (HDI). ${ }^{2}$ Gender inequality was continuous and measured with the Gender Inequality Index. ${ }^{2}$ Whether the household lived in an urban or rural community was dichotomously coded ( $0=$ rural, $1=$ urban $)$. To account for the timing of data collection, we also included the MICS round, which was dichotomously coded ( $0=$ round $4,1=$ round 5$)$.

\section{Analytical strategy}

All analyses were conducted in Stata V.15.1. ${ }^{29}$ We limited our analytical sample to household respondents who had 
Table 1 Countries included in analytical sample ( $\mathrm{N}=65$ countries, 613861 households)

\begin{tabular}{|c|c|c|}
\hline Country & $\mathbf{N}$ & $\begin{array}{l}\% \text { of analytical } \\
\text { sample }\end{array}$ \\
\hline Afghanistan & 11544 & 1.88 \\
\hline Algeria & 16788 & 2.73 \\
\hline Argentina & 11768 & 1.92 \\
\hline Bangladesh & 38717 & 6.31 \\
\hline Barbados & 886 & 0.14 \\
\hline Belarus & 3334 & 0.54 \\
\hline Belize & 5478 & 0.89 \\
\hline Benin & 9681 & 1.58 \\
\hline Bosnia and Herzegovina & 3409 & 0.56 \\
\hline Cameroon & 5981 & 0.97 \\
\hline Central Africa Republic & 8165 & 1.33 \\
\hline Chad & 12265 & 2.00 \\
\hline Costa Rica & 3040 & 0.50 \\
\hline Côte d'Ivoire & 7455 & 1.21 \\
\hline $\begin{array}{l}\text { Democratic Republic of the } \\
\text { Congo }\end{array}$ & 8778 & 1.43 \\
\hline Dominican Republic & 18946 & 3.09 \\
\hline El Salvador & 8146 & 1.33 \\
\hline Eswatini & 5935 & 0.97 \\
\hline Ghana & 8846 & 1.44 \\
\hline Guinea & 6136 & 1.00 \\
\hline Guinea Bissau & 5158 & 0.84 \\
\hline Guyana & 3112 & 0.51 \\
\hline Indonesia & 3767 & 0.61 \\
\hline Iraq & 27906 & 4.55 \\
\hline Jamaica & 2647 & 0.43 \\
\hline Kazakhstan & 14253 & 2.32 \\
\hline Kenya & 2540 & 0.41 \\
\hline Kosovo & 2879 & 0.47 \\
\hline Kyrgyzstan & 4244 & 0.69 \\
\hline Laos & 14469 & 2.36 \\
\hline Macedonia & 2274 & 0.37 \\
\hline Madagascar (South) & 2345 & 0.38 \\
\hline Malawi & 19268 & 3.14 \\
\hline Mali & 2228 & 0.36 \\
\hline Mauritania & 16357 & 2.66 \\
\hline Mexico & 7557 & 1.23 \\
\hline Moldova & 3119 & 0.51 \\
\hline Mongolia & 17128 & 2.79 \\
\hline Montenegro & 1989 & 0.32 \\
\hline Nepal & 12239 & 1.99 \\
\hline Nigeria & 41858 & 6.82 \\
\hline Pakistan & 58318 & 9.50 \\
\hline Palestine refugees in Lebanon & 2525 & 0.41 \\
\hline
\end{tabular}

Continued
Table 1 Continued

\begin{tabular}{lrl}
\hline Country & N & $\begin{array}{l}\text { \% of analytical } \\
\text { sample }\end{array}$ \\
\hline Panama & 6313 & 1.03 \\
\hline Paraguay & 4651 & 0.76 \\
\hline Republic of the Congo & 7860 & 1.28 \\
\hline Sao Tome and Principe & 2175 & 0.35 \\
\hline Senegal (Dakar City) & 3177 & 0.52 \\
\hline Serbia & 8282 & 1.35 \\
\hline Sierra Leone & 9166 & 1.49 \\
\hline Somalia & 7982 & 1.30 \\
\hline St. Lucia & 587 & 0.10 \\
\hline State of Palestine & 16552 & 2.70 \\
\hline Sudan & 11272 & 1.84 \\
\hline Suriname & 3769 & 0.61 \\
\hline Thailand & 18863 & 3.07 \\
\hline The Gambia & 6220 & 1.01 \\
\hline Togo & 4482 & 0.73 \\
\hline Trinidad and Tobago & 1990 & 0.32 \\
\hline Tunisia & 4077 & 0.66 \\
\hline Turkmenistan & 3449 & 0.56 \\
\hline Ukraine & 4371 & 0.71 \\
\hline Uruguay & 2037 & 0.33 \\
\hline Vietnam & 11599 & 1.89 \\
\hline Zimbabwe & 11509 & 1.87 \\
\hline & & \\
\hline
\end{tabular}

no missing data on our outcome variable, leaving a final sample size of 613861 households across 65 countries. We then screened for missing data on our predictor variables. In general, missing data were few, ranging from $0 \%$ to $5 \%$ on most variables. The greatest amount of missing data was found on gender inequality, which had 14\% missing data. We also scanned for outliers and instances of multicollinearity, neither of which were found. We ran twolevel models, with individuals nested within countries to account for the fact that observations from different families within the same country were likely to be correlated..$^{30}$ Additionally, because research has demonstrated that the relationship between child age and likelihood of spanking is non-linear (ie, the likelihood of being spanked is highest between child ages 3 and 5), we included the quadratic term for children's age as a predictor in the model. Child age was grand mean centred to promote interpretability.

To determine which microsystem and macrosystem predictors were significantly associated with spanking, we estimated multilevel logistic regression models, which provided OR coefficients. Stata, the statistical software we employed for this analysis, handles missing data in multilevel models using listwise deletion, which means that if a variable contained missing data, the corresponding rows of data were excluded. We first ran a model that only examined microsystem predictors of spanking (Model 1), 
Table 2 Descriptive statistics of study variables ( $\mathrm{N}=613861$ households)

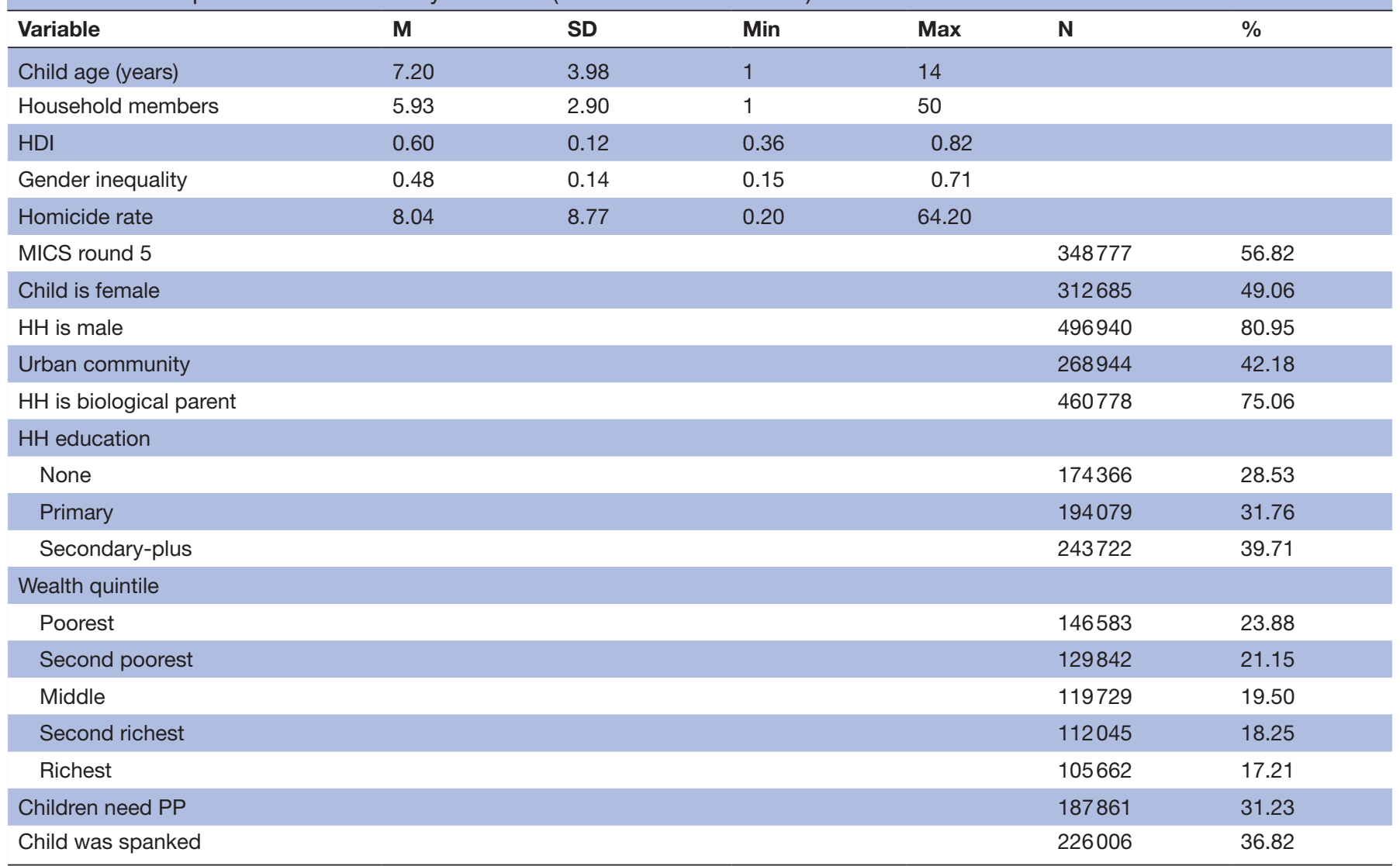

Number of household members was capped at 50 .

.HDI, Human Development Index; HH, household survey respondent, usually the head of household; MICS, Multiple Indicator Cluster Surveys; PP, physical punishment.

which included child age, child sex, head-of-household sex, head-of-household relation to the child, number of household members, head-of-household educational attainment, attitudes toward physical punishment and household wealth quintile. We then introduced macrolevel predictors into the model (Model 2). At the countrylevel, these predictors included homicide rate, HDI score, unemployment rate and gender inequality. Ten countries did not have data on one or more of the macrolevel predictors; thus, Model 2 only includes 55 countries. At the community-level we included an indicator for whether the household was in an urban or rural community. We also included an indicator for MICS round to account for the timing of the survey.

\section{RESULTS}

Table 1 presents the number of participants within each country. Table 2 presents study descriptive statistics. Approximately $37 \%$ of respondents indicated that the focal child was spanked within the past month, and approximately $31 \%$ of respondents believed that children need physical punishment in order to be raised properly. The average age of focal children was 7.20 years $(\mathrm{SD}=3.98)$ and slightly over half were male $(51 \%)$. Most household questionnaire respondents were men $(81 \%)$ and were the focal child's biological parent (75\%). On average, there were six members of the household $(\mathrm{SD}=2.90)$. The majority of families lived in a rural community $(58 \%)$.

\section{Multilevel logistic regression models}

We ran an unconditional model, where the mean of spanking was estimated, accounting for clustering within countries. We then estimated the intraclass correlation coefficient, which revealed that $10 \%$ of the variation in spanking could be explained by country. Results from multilevel logistic regression models can be found in table 3. In Model 1 (microsystem predictors only), nearly all microsystem predictors were associated with spanking. Model 2 provides estimates of microsystem and macrosystem predictors estimated together. A number of variables were risk factors of spanking. Each additional person in the household was associated with a $3 \%$ increase in the odds of the focal child being spanked $(\mathrm{OR}=1.03,95 \% \mathrm{CI}: 1.02$ to 1.03$)$. Compared with the head-of-household having no education, the head-ofhousehold having primary education was associated with a $4 \%$ increase in the odds of the focal child being spanked (OR=1.04, 95\% CI: 1.03 to 1.06$)$. The household respondent being the biological parent was associated with a $24 \%$ increase in the odds of the focal child being spanked (OR=1.24, 95\% CI: 1.22 to 1.26$)$. The household 
Table 3 Results from multilevel logistic regression analyses examining predictors of spanking

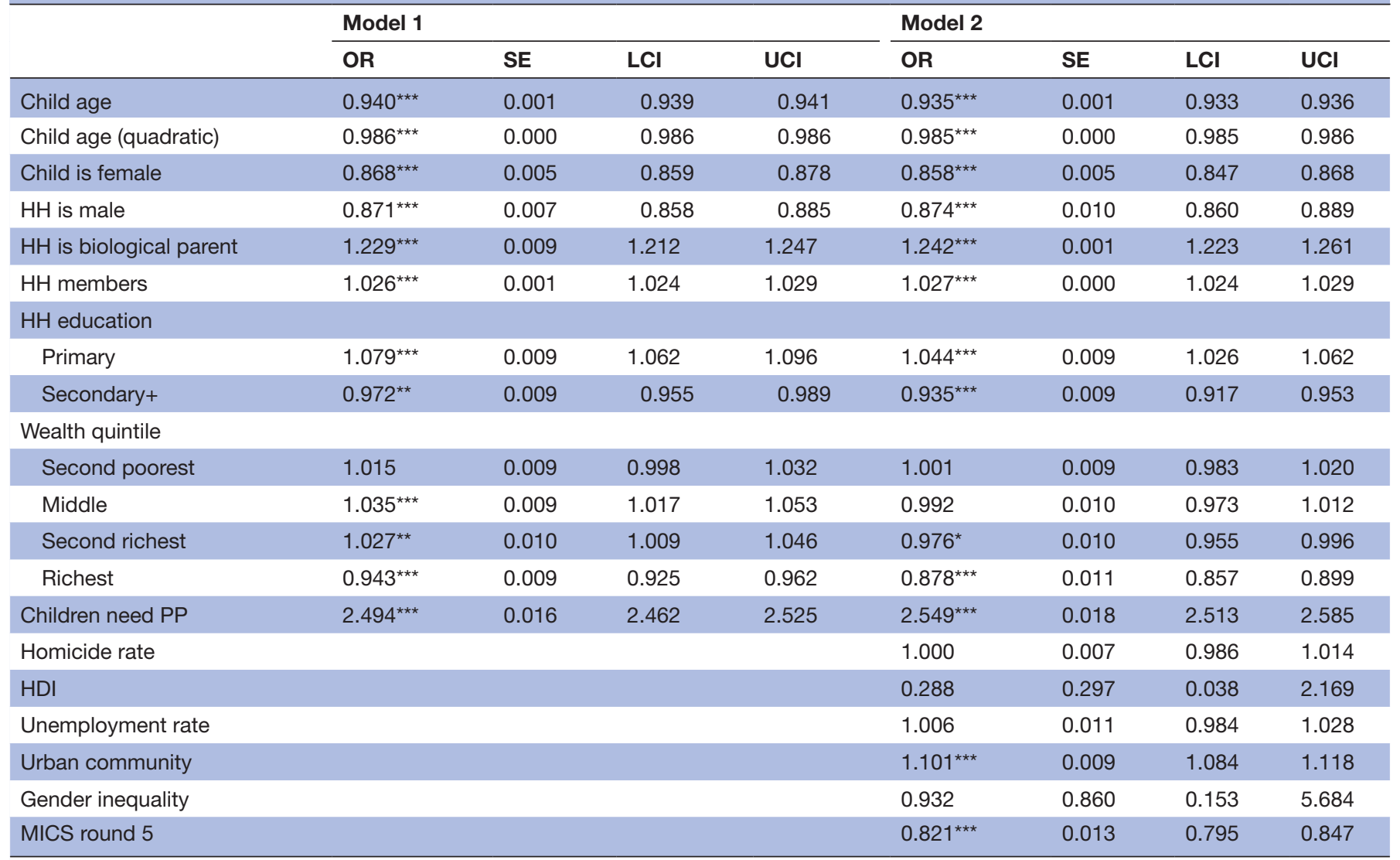

Note: Comparison variable for Education is 'none', comparison variable for wealth quintile is 'poorest'.

Model 1: $\mathrm{N}=598835$ households, 65 countries. AIC: 717 034.1, BIC: 717203.6.

Model 2: $\mathrm{N}=502519$ households, 55 countries. AIC: 594 766.0, BIC: 594999.6.

The 10 countries missing from Model 2 are Barbados, Eswatini, Guinea, Kosovo, Madagascar (south), Nigeria, Somalia, State of Palestine, Sudan and Trinidad/Tobago.

${ }^{*} \mathrm{p}<.05,{ }^{* *} \mathrm{p}<.01,{ }^{* * *} \mathrm{p}<.001$

HDI, Human Development Index; HH, household survey respondent, usually the head of household; LCI, lower bound of 95\% Cl; MICS, Multiple Indicator Cluster Surveys; PP, physical punishment; UCI, upper bound of $95 \% \mathrm{Cl}$.

respondent believing that a child needs physical punishment in order to be raised properly was associated with a $155 \%$ increase in the odds of the focal child being spanked (OR=2.55, 95\% CI: 2.51 to 2.59 ).

Other microsystem variables were protective factors against spanking. Compared with the head-of-household having no education, the head-of-household having a secondary education or higher was associated with a $6 \%$ decrease in the odds of the focal child being spanked (OR=0.94, 95\% CI: 0.92 to 0.95). A 1-year increase in children's age was associated with a $6 \%$ decrease in the odds of the focal child being spanked ( $\mathrm{OR}=0.94,95 \%$ CI: 0.93 to 0.94 ). The focal child being female was associated with a $14 \%$ decrease in the odds of the focal child being spanked (OR $=0.86,95 \%$ CI: 0.85 to 0.87$)$. The head of the household being male was associated with a $13 \%$ decrease in the focal child being spanked ( $\mathrm{OR}=0.87,95 \% \mathrm{CI}$ : 0.86 to 0.89 ). Compared with being in the poorest household wealth quintile, being in the second richest $(\mathrm{OR}=0.98$, 95\% CI: 0.96 to 1 ) or richest ( $\mathrm{OR}=0.88,95 \%$ CI: 0.86 to $0.90)$ quintile was associated with a decrease in the odds of the focal child being spanked. In terms of macrosystem variables, the community of the household was a risk factor of spanking, as the household being in an urban community was associated with a $10 \%$ increase in the odds of the focal child being spanked (OR=1.10, 95\% CI: 1.08 to 1.12). Additionally, compared with the fourth round of MICS data collection, the fifth round was associated with a decrease in the odds of the focal child being spanked ( $\mathrm{OR}=0.82,95 \%$ CI: 0.80 to 0.85$)$, perhaps due to the inclusion of 1-year-olds during round 5 , differences between countries across rounds (only seven countries participated in both rounds), and that the prevalence of spanking may be declining globally over time.

\section{DISCUSSION}

Using an ecological perspective, ${ }^{18}$ this study examined micro-level and macro-level predictors of spanking in 613861 households across 65 LMICs. Organisations around the globe are calling for the elimination of violence against children, including the use of spanking. ${ }^{515}$ One strategy to reduce violence against children is to ban spanking at the country level. ${ }^{3132}$ Other strategies include 
parenting education and intervention at the microsystem level. ${ }^{33}$ This study suggests that targeting interventions at both the microsystem and macrosystem is necessary to reduce violence against children.

Specifically, results of this study show that caregiver attitudes about physical punishment are powerful predictors of spanking, echoing prior research using MICS data showing that caregiver attitudes about spanking were a strong predictor of child abuse ${ }^{3}$ as well as US studies showing similar associations. ${ }^{345}$ In fact, in this study, caregiver attitudes toward spanking were linked to violence against children over and above numerous contextual factors. This suggests that in order to reduce violence against children worldwide, parenting interventions are warranted.

Indeed, the United Nations has called attention to the need 'to stop parents from using violent or other cruel or degrading punishments through supportive and educational, not punitive, interventions'. ${ }^{1}$ The WHO supports the Parenting for Lifelong Health (PLH) programme, which is currently being implemented in low-resource and LMIC settings. ${ }^{36}$ Another programme is Positive Discipline in Everyday Parenting (PDEP), a universal intervention that aims to change parental attitudes toward physical punishment and change parental roles to one of collaboration and mentorship as opposed to coercion and control. ${ }^{37}$ International studies suggest that PDEP can reduce parental approval of physical punishment and improve child outcomes. ${ }^{38-40}$ However, for both PLH and PDEP, there is a need for randomised controlled trials to establish rigorous evidence of effectiveness.

Results of this study indicate that macrosystem factors are also important targets for intervention, particularly in urban environments. Population density may contribute to the 'spread' of social norms that support the use of physical punishment. In addition, families who live in urban communities in LMICs may have less access to the economic and social resources in their community, ${ }^{41}$ which puts them at risk for using violent forms of discipline. Population-based public education campaigns that educate communities about the negative effects of spanking may be beneficial in dense urban areas. ${ }^{4-45}$ The Better Parenting Programme is a public education intervention to increase parental knowledge of child development. In Jordan, the Better Parenting Programme was associated with improved parenting knowledge, increased parental involvement and increased utilisation of explanations when disciplining children. ${ }^{46}$ Additionally, as societal violence, family violence and violence against children are inextricably connected, ${ }^{47} 48$ education campaigns against other forms of violence may indirectly reduce violent forms of punishment, such as spanking. For example, the Global 16 Days Campaign launched by the Center for Women's Global Leadership is a public education campaign that has been used worldwide to end gender-based violence (GBV) ${ }^{49}$ Empirical findings suggest the Global 16 Days Campaign has effectively raised awareness about GBV on local, regional and international levels, and has led to a multilevel mobilisation of women's organisations across the globe.$^{50}$ Implementing bans on spanking may also be an effective macro-level intervention. Country-level spanking bans are associated with changes in parental attitudes toward spanking over time. ${ }^{51} 52$

\section{Strengths and limitations}

Study limitations should be considered when interpreting the results. Our study included data from 613861 households in 65 LMICs with information gathered using representative sampling methods and standardised interview protocols, thus providing the most global perspective to date on the predictors of spanking. Multilevel modelling accounted for between-country and within-country variation in spanking. However, the cross-sectional nature of the analyses restricts the interpretation of our results to associations that are not causal. Our large sample size likely resulted in sufficient statistical power to detect smaller associations; thus, $\mathrm{p}$ values should not be the only criterion used to decipher meaningful effects- the size of the ORs, SEs and CIs should also be considered. When considering an outcome such as spanking, which is a violation of human rights and consistently associated with poorer future outcomes, ${ }^{18}$ even small associations-especially when multiplied across large numbers of children and families-could help to inform more holistic approaches to ending violence against children. The analyses do not elucidate the mechanisms linking microsystem and macrosystem variables to spanking. For example, higher household wealth may reflect access to greater social and economic resources that decrease the likelihood of spanking. ${ }^{53}$ Indeed, the directionality of the relationship between the middle and second-richest household wealth quintile and spanking switched after macro-level predictors were accounted for in the model, revealing that these associations may be dependent on other factors. Empirical examination of these mechanisms is necessary. The variables in this study are based on self-report data, which are subject to self-presentation bias. ${ }^{54}$ Respondents may not be aware of all instances of spanking in the household, increasing the possibility of under-reporting or misreport of spanking in the home.

\section{Conclusion}

Spanking is a global public health concern, as spanking is the most prevalent form of physical violence against children worldwide. Caregivers' beliefs that physical punishment is necessary was most strongly associated with the likelihood of spanking. At the macro-level, living in an urban community was associated with spanking. The results indicate that both micro-level and macro-level interventions are likely necessary in order to reduce violence against children. Parenting programmes such as the WHO PLH and PDEP programme have been successfully implemented in LMICs. Country-level bans, educational campaigns and campaigns against violence against women may also serve the broader goal of reducing violence against children. Country-specific cultural factors should be considered prior to intervention implementation. 
Acknowledgements The authors would like to thank Dr Joan Durrant for her feedback on this manuscript.

Contributors KPW was involved in study conceptualisation, manuscript writing and editing and completion of data analysis. AG-K was involved in study conceptualisation, manuscript writing and editing and data analysis supervision. GTP and JC were involved in data collection, data cleaning and manuscript writing and editing. SL was involved in manuscript writing and editing and data analysis supervision.

Funding The authors gratefully acknowledge use of the services and facilities of the Population Studies Center at the University of Michigan, funded by the Eunice Kennedy Shriver National Institute of Child Health and Human Development of the National Institutes of Health under Award Number P2CHD041028. The content is solely the responsibility of the authors and does not necessarily represent the official views of the National Institutes of Health.

Competing interests None declared.

Patient and public involvement Patients and/or the public were not involved in the design, or conduct, or reporting, or dissemination plans of this research.

Patient consent for publication Not required.

Ethics approval Our analysis was deemed exempt from the University of Michigan Institutional Review Board (HUM00191904).

Provenance and peer review Not commissioned; externally peer reviewed.

Data availability statement Data are available in a public, open access repository. Data are publicly available via the UNICEF MICS website.

Open access This is an open access article distributed in accordance with the Creative Commons Attribution Non Commercial (CC BY-NC 4.0) license, which permits others to distribute, remix, adapt, build upon this work non-commercially, and license their derivative works on different terms, provided the original work is properly cited, appropriate credit is given, any changes made indicated, and the use is non-commercial. See: http://creativecommons.org/licenses/by-nc/4.0/.

\section{ORCID iD}

Kaitlin Paxton Ward http://orcid.org/0000-0003-0780-2359

\section{REFERENCES}

1 Svevo-Cianci KA, Herczog M, Krappmann L, et al. The new UN CRC General Comment 13: "The right of the child to freedom from all forms of violence"--changing how the world conceptualizes child protection. Child Abuse Negl 2011;35:979-89 https://doi.org/10. 1016/j.chiabu.2011.09.006

2 United Nations Development Programme. Human development report 2016: human development for everyone. New York: United Nations Development Programme, 2016.

3 Akmatov MK. Child abuse in 28 developing and transitional countries--results from the Multiple Indicator Cluster Surveys. Int $J$ Epidemiol 2011;40:219-27.

4 Pinheiro P. World Report on violence against children. In: In the United Nations secretary-general's study on violence against children. Vol. 10, 2006

5 UNICEF. A familiar face: violence in the lives of children and adolescents 2017, 2020. https://www.unicef.org/publications/index 101397.html

6 Cuartas J, McCoy DC, Rey-Guerra C, et al. Early childhood exposure to non-violent discipline and physical and psychological aggression in low- and middle-income countries: national, regional, and global prevalence estimates. Child Abuse Negl 2019;92:93-105.

7 Un General assembly A/RES/62/141 2008 https://www.un.org/en/ development/desa/population/migration/generalassembly/docs/ globalcompact/A_RES_62_141.pdf

8 Gershoff ET, Grogan-Kaylor A. Spanking and child outcomes: old controversies and new meta-analyses. J Fam Psychol 2016;30:453-69.

9 Gershoff ET, Sattler KMP, Ansari A. Strengthening causal estimates for links between spanking and children's externalizing behavior problems. Psychol Sci 2018;29:110-20.

10 Gershoff ET, Lansford JE, Sexton HR, et al. Longitudinal links between spanking and children's externalizing behaviors in a national sample of white, black, Hispanic, and Asian American families. Child Dev 2012;83:838-43.

11 Cuartas J, McCoy DC, Grogan-Kaylor A, et al. Physical punishment as a predictor of early cognitive development: evidence from econometric approaches. Dev Psychol 2020;56:2013-26.
12 Durrant JE, Stewart-Tufescu A, Afifi TO. Recognizing the child's right to protection from physical violence: an update on progress and a call to action. Child Abuse Negl 2020;110:104297.

13 End Violence Against Children. Progress MAP, 2020. Available: https://www.end-violence.org

14 World Health Organization. INSPIRE seven strategies for ending violence against children. World Health Organization, 2016: 1-108. https://www.who.int/publications/i/item/inspire-seven-strategies-forending-violence-against-children

15 Sege RD, Siegel BS, et al, Committee on Psychosocial Aspects of Child and Family Health. Effective discipline to raise healthy children Pediatrics 2018;142:e20183112.

16 Elgar FJ, Donnelly PD, Michaelson V, et al. Corporal punishment bans and physical fighting in adolescents: an ecological study of 88 countries. BMJ Open 2018;8:e021616

17 Gershoff ET, Durrant JE. Legal prohibitions of physical punishment. In: Gershoff ET, Lee SJ, eds. Ending the physical punishment of children: a guide for clinicians and practitioners. 1st edn. American Psychological Association, 2020: 155-63.

18 Bronfenbrenner U. Ecological models of human development. In: International encyclopedia of education. 2nd edn. Oxford: Elsevier, 1994.

19 Finkelhor D, Turner H, Wormuth BK, et al. Corporal punishment: current rates from a national survey. J Child Fam Stud 2019;28:1991-7.

20 Ateah CA, Durrant JE. Maternal use of physical punishment in response to child misbehavior: implications for child abuse prevention. Child Abuse Negl 2005;29:169-85.

21 Jocson RM, Alampay LP, Lansford JE. Predicting Filipino mothers' and fathers' reported use of corporal punishment from education, authoritarian attitudes, and endorsement of corporal punishment. Int J Behav Dev 2012;36:137-45.

22 Wolf S, Suntheimer NM. Predictors of parental disciplinary practices and associations with child outcomes among Ghanaian preschoolers. Child Youth Serv Rev 2020;112:104518.

23 Klevens J, Ports KA. Gender inequity associated with increased child physical abuse and neglect: a Cross-Country analysis of populationbased surveys and country-level statistics. J Fam Violence 2017;32:799-806.

24 Lansford JE, Godwin J, Uribe Tirado LM, et al. Individual, family, and culture level contributions to child physical abuse and neglect: a longitudinal study in nine countries. Dev Psychopathol 2015;27:1417-28.

25 Lansford JE, Deater-Deckard K. Childrearing discipline and violence in developing countries. Child Dev 2012;83:62-75.

26 Straus MA, Hamby SL, Finkelhor D, et al. Identification of child maltreatment with the parent-child conflict tactics scales: development and psychometric data for a national sample of American parents. Child Abuse Negl 1998;22:249-70.

27 United Nations Development Programme. Statistics homicide, 2013. Available: http://www.unodc.org/unodc/en/data-and-analysis/ homicide.html

28 World Bank. World bank open data, 2020. Available: https://data. worldbank.org

29 StataCorp LLC. StataCorp Stata statistical software: release 15.1. College Station, TX, 2017.

30 Hox JJ, Moerbeek M, van de Schoot R. Multilevel analysis 2017.

31 Zolotor AJ, Puzia ME. Bans against corporal punishment: a systematic review of the laws, changes in attitudes and behaviours. Child Abuse Rev, 2010:19:229-47.

32 Lansford JE, Cappa C, Putnick DL, et al. Change over time in parents' beliefs about and reported use of corporal punishment in eight countries with and without legal bans. Child Abuse Negl 2017;71:44-55.

33 Gershoff ET, Lee SL. Ending the physical punishment of children: a guide for clinicians and practitioners. 1st edn. American Psychological Association, 2020.

34 Berlin LJ, Ispa JM, Fine MA, et al. Correlates and consequences of spanking and verbal punishment for low-income White African American, and Mexican American toddlers. Child Dev 2009;80:1403-20.

35 Combs-Orme T, Cain DS. Predictors of mothers' use of spanking with their infants. Child Abuse Negl 2008;32:649-57.

36 World Health Organization. Parenting for lifelong health (PLH), 2020. Available: https://www.who.int/violence_injury_prevention/violence/ child/plh/en

37 Durrant JE. Positive discipline in everyday parenting (PDEP). In: Gershoff ET, Lee SJ, eds. Ending the physical punishment of children: a guide for clinicians and practitioners. 1st edn. American Psychological Association, 2020: 89-99. 
38 Durrant JE, Barker L, Jones AD. Preventing punitive violence against children: a three-province evaluation of a primary prevention program. Final report to the prairie action Foundation. Winnipeg, Manitoba: Mosaic Newcomer Family Resource Network, Saskatchewan Prevention Institute, \& Alberta Home Visitation Network Association, 2018.

39 Mori I, Mochizuki R, Stewart-Tufescu A. Transforming parents' beliefs about physical punishment through 'Positive Discipline in Everyday Parenting' in Japan. Paper presented at the Conference of the International Society for Prevention of Child Abuse and Neglect, Calgary, Alberta, Canada 2016.

40 Stewart-Tufescu A, Ateah C, Barker L. Shifting attitudes toward physical punishment in a multicultural context: the case of Canada. paper presented at the conference of the International Society for prevention of child abuse and neglect, Calgary, Alberta, Canada 2016.

41 Cohen B. Urbanization in developing countries: current trends, future projections, and key challenges for sustainability. Technol Soc 2006;28:63-80.

42 Durrant JE, Olsen GM. Parenting and public policy: Contextualizing the Swedish corporal punishment ban. J Soc Welf Fam Law 1997;19:443-61.

43 Durrant JE, Smith AB. Global pathways to abolishing physical punishment: realizing children's rights. New York, NY: Routledge, 2011.

44 Gagné M-H, Bélanger-Gravel A, Clément Marie-Ėve, et al. Recall and understanding of a communication campaign designed to promote positive parenting and prevent child maltreatment. Prev Med Rep 2018;12:191-7.

45 Poole MK, Seal DW, Taylor CA. A systematic review of universal campaigns targeting child physical abuse prevention. Health Educ Res 2014;29:388-432.
46 Al-Hassan SM, Obeidat OM, Lansford JE. An evaluation of the implementation of public kindergartens in Jordan. In: Thompson SB, ed. Kindergartens: programs, functions and outcomes. Hauppauge, NY: Nova Science, 2010: 179-90.

47 Lansford JE, Dodge KA. Cultural norms for adult corporal punishment of children and societal rates of endorsement and use of violence. Parent Sci Pract 2008;8:257-70.

48 Straus MA. True primordial violence: corporal punishment by parents, cognitive development and crime. Walnut Creek, CA: Alta Mira Press, 2014.

49 Center for Women in Global Leadership. Global 16 days campaign, 2020. Available: https://16dayscampaign.org/

50 Thompson C. A life of its own: an assessment of the 16 days of activism against gender-based violence campaign. Center for women's global leadership 2017 https://16dayscampaign.org/wpcontent/uploads/2018/11/16-Days-Campaign-Assessment.pdf

51 Save the Children. Changing attitudes to physical punishment of children in Aotearoa New Zealand, 2018. Available: https:// resourcecentre.savethechildren.net/node/14309/pdf/stc-childrensreport-digital.pdf

52 Sweden S. Spanking and other forms of physical punishment: A study of adults' and middle school students' opinions, experience and knowledge. Demografiska Rapporter 1996;1.

53 Bornstein MH, Cote LR, Haynes OM, et al. Parenting knowledge: experiential and sociodemographic factors in European American mothers of young children. Dev Psychol 2010;46:1677-93.

54 Bornstein MH, Putnick DL, Lansford JE, et al. Mother and father socially desirable responding in nine countries: two kinds of agreement and relations to parenting self-reports. Int J Psychol 2015;50:174-85. 